\title{
Recorregut de recerca geològica i mineralògica per la comarca del solsonès (amb inici a la de I'Alt Urgell): des del Coll del Port al Port del Comte, a Colldejou i al mirador de Vilamala
}

Josep Maria Mata-Perelló

Joaquim Sanz Balagué

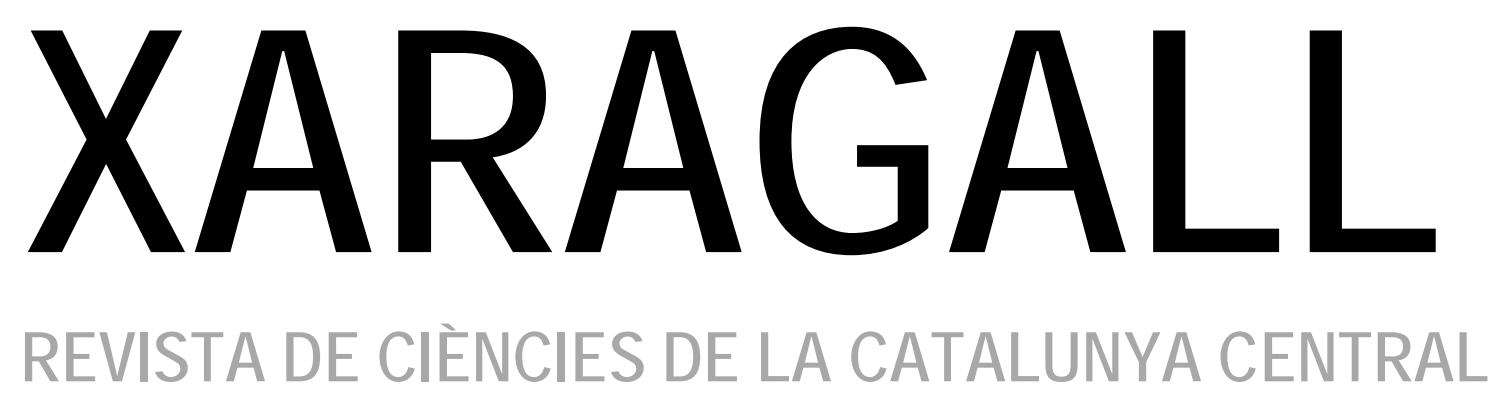

ก. 6

JUNY 2015 


\title{
RECORREGUT DE RECERCA GEOLÒGICA I MINERALÒGICA PER LA COMARCA DEL SOLSONÈS (AMB INICI A LA DE L'ALT URGELL): DES DEL COLL DEL PORT AL PORT DEL COMTE, A COLLDEJOU I AL MIRADOR DE VILAMALA
}

\author{
Josep Maria Mata-Perelló \\ Museu de geologia Valentí Masachs, Escola Politècnica Superior d'Enginyeria de Manresa \\ (EPSEM), Universitat Politècnica de Catalunya · BarcelonaTech (UPC), 08272 Manresa, Spain
}

\section{Joaquim Sanz Balagué}

Departament d'Enginyeria Minera i Recursos Naturals (EMRN), Escola Politècnica Superior d'Enginyeria de Manresa (EPSEM), Universitat Politècnica de Catalunya . BarcelonaTech (UPC), 08272 Manresa, Spain

Paraules clau: fjfjlsfj, rnssñfmsmomref, erisorjsofjsdñfjñf...

\section{Resum}

Itinerari realitzat el 13 de juliol de 2014. En aquesta ocasió, el recorregut de l'itinerari discorrerà, en la seva quasi totalitat pel Sistema Pirinenc. I ho farà per dues de les seves sotsunitats.. Així, es circularà per diferents de les seves sots unitats: pel Mantell del Pedraforca Inferior i pel Mantell del Cadí. Tanmateix, els darrers trams del recorregut, els farà per la Depressió Geològica de L'Ebre, per la Zona de l'Avant País Plegat.

Així, el recorregut s'iniciarà dintre dels afloraments mesozoics (del Juràssic i del Cretàcic) que formen part del Mantell del Pedraforca Inferior els quals es troben en contacte amb els sediments cenozoics del Mantell del Cadí, al Coll del Port. Finalitzarà entre depòsits de sediments postorogènics al Mirador de Vilamala.

Per altra banda, tot i que el recorregut de l'itinerari transitarà per la comarca del Solsonès (entre el Coll del Port i Vilamala). Tot i això, s' haurà inicial al límit amb la comarca de l'Alt Urgell 


\section{Objectius fonamentals}

Es centraran en els aspectes geològics, geomorfològics i mineralògics que apuntarem a continuació, d'acord amb el sentit de la marxa del recorregut:

1. Observació de l'estructura de la Zona Sudpirinenca, (i més concretament les seves unitats, com el Mantell del Pedraforca Interior i el Mantell del Cadi). En conjunt, els anirem veient al llarg dels primers trams del recorregut, especialment el segon.

2. Observació dels afloraments del Mantell del Pedraforca Inferior, que nosaltres trobarem pels voltants del Coll de Port. Així, veurem afloraments dels materials mesozoics (del Juràssic i del Cretàcic).

3. Observació dels afloraments del Mantell del Cadí, que nosaltres al Coll de Port i a diferents indrets del Port del Compte. En aquests trams trobarem afloraments dels materials cenozoics, fonamentalment del Paleocè i de l'Eocè.

4. Observació dels afloraments dels materials cenozoics (de l'Eocè i de l'Oligocè) que trobarem a la Zona de l'Avant País (de la Depressió Geològica de l'Ebre). Aquests materials els trobarem entre el Port del Compte i la fi del recorregut

5. Observació de les estructures de les unitats geològiques acabades d'esmentar i de les relacions existents entre elles.

6. Reconeixement de diverses mineralitzacions situades al llarg del recorregut, que anem trobant d'acord amb el sentit de la marxa, en concret de les mineralitzacions bauxitíferes de rebliment de cavitats d'origen kàrstic, situades al Coll de Port

7. Reconeixement de les explotacions mineres, antigues i actuals, relacionades amb les mineralitzacions esmentades a l'apartat anterior.

8. Observació dels impactes produïts per les explotacions anteriors, sobre el Medi Natural; així com de les possibles restauracions, si s'han dut a terme.

9. Observació, al llarg del recorregut, dels diferents indrets relacionats amb el Patrimoni Geològic i Miner. 


\section{Antecedents}

En relació a aquest recorregut, no hi ha cap antecedent global. Això si: hi ha diversos antecedents parcials nostres, especialment relacionats amb el Coll de Port. Entre aquests farem esment dels següents: MATA-PERELLÓ (1997a, 1997b, 2005, 2007, 2012, 2013a i 2013b). Així com MATA - PERELLÓ i SANZ BALAGUÉ (2014).

Pel que toca al coneixement de les estructures geològiques que veurem en aquest itinerari hi ha l'antecedent local de BERASTEGUI et altri (1993); aquest antecedent es relatiu a un treball de l'IGME, relatiu a l'àrea recorreguda. Altres antecedents, de caràcter estructurals, i relatius al conjunt dels Països Catalans, són els següents: RIBA et altri (1976) i GUIMERÀ (1982); així com SGC (1990).

Finalment, i pel que fa a les mineralitzacions que trobarem al llarg del recorregut, ens referirem a: MATA-PERELLÓ (1991). Aquest treball fa referència al conjunt de les mineralitzacions de Catalunya.

Evidentment, totes aquestes referències bibliogràfiques, figuraran degudament relacionades, per ordre alfabètic, dintre de l'apartat dedicat a les REFERÈNCIES BIBLIOGRÀFIQUES.

\section{Recorregut de l'itinerari}

El recorregut d'aquest itinerari començarà al Coll del Port, al límit de les comarques de l'Alt Urgell i del Solsonès. Després de fer les primeres aturades, el recorregut es dirigirà cap al Sud, cap a la Coma, seguint la carretera local LV - 4012.

Tot i així, en trobar el trencall que es dirigeix cap a les pistes d'esquí del Port del Compte, ens caldrà agafar-la, per tal d'anar-hi. Després de fer un recorregut per elles i de fer varies aturades, ens caldrà anar cap el Coll de Jou. Aquí, trobarem la carretera local LV - 4241, per la qual ens caldrà seguir, en el seu sentit meridional, per tal d'arribar al Mirador de Vilamala, per on finalitzarem aquest itinerari.

\section{Advertiments previs}

Com en altres recorreguts de RECERCA GEOLÒGICA I MINERALÒGICA... si es disposa del temps suficient, poden efectuar-se passant per totes les parades i filloles. En cas contrari, recomanem prescindir de les anomenades PARADES - CONDICIONALS.

També recomanem que es demani informació sobre l'estat dels diferents trams de les pistes forestals, per les quals s' ha de circular, en el recorregut de l'itinerari, per tal d'evitar problemes secundàries.).

Per altra banda, i a l'igual que en altres recorreguts semblants, recomanem tenir el màxim de cura i de respecte, entorn de la Natura que ens rodeja. 


\section{Descripció de l'itinerari}

En aquest recorregut hem situat, com ja és habitual en tots els itineraris, una sèrie d'ESTACIONS o de PARADES, que anirem veient a continuació. En cada cas, els hi donarem una denominació que podrà correspondre a algun paratge proper. També indicarem el terme municipal i la comarca on es troba.

Per altra banda, en cadascuna de les parades, indicarem entre parèntesi el número del mapa topogràfic, a escala 1:50.000, on es troba situada la parada considerada. En aquesta ocasió utilitzarem dos fulls de la CME ("Cartografia Militar de España"): concretament, els fulls 254 (o de Gósol) i el 292 (o de Sant Llorenç de Morunys)..

Així, passarem a continuació, a fer una referència ordenada, de les diferents aturades que composen el recorregut del present itinerari.

\subsection{Parada 1. COLL DE PORT, (termes municipals de Josa i Tuixén i la Coma, comarques de l'Alt Urgell i del Solsonès). (Full 254).}

El recorregut d'aquest itinerari el començarem en aquest lloc, situat al límit de les comarques del Solsonès (per on seguirem el recorregut) i de l'Alt Urgell. Aquí s'hi arriba seguint la carretera LV - 4012, venint des de Tuixén o des de Sant Llorenç de Morunys.

En aquest indret es troben afloraments dels materials carbonatats del Juràssic (i també del cretàcic) del Mantell del Pedraforca Inferior, visibles al Nord. Tot i això, estan en contacte amb sediments eocens del Mantell de Cadí (que aquí constitueix la Serra del Port de Compte). Aquest contacte, es realitza per encavalcament del primer sobre el segon, com hem abans

Després, d'aquest indret de l'aturada, es pot gaudir d'un immillorable lloc d'observació. Així, d'aquest indret, mirant cap al Nord, es pot gaudir d'una bona observació dels dos mantells acabats d'esmentar: entre el Mantell del Pedraforca Inferior Fonamentalment amb els relleus dels voltants de Tuixén i el Cadinell) i el Mantell del Cadí (amb la Serra del Cadí). Molt més cap al Nord, i en dies extraordinàriament clars, es pot gaudir d'una bona visió dels relleus de la zona axial (dels anomenats Apilaments Antiformes de la Zona Axial; això sí, molt llunyans. (fotografia 1). 


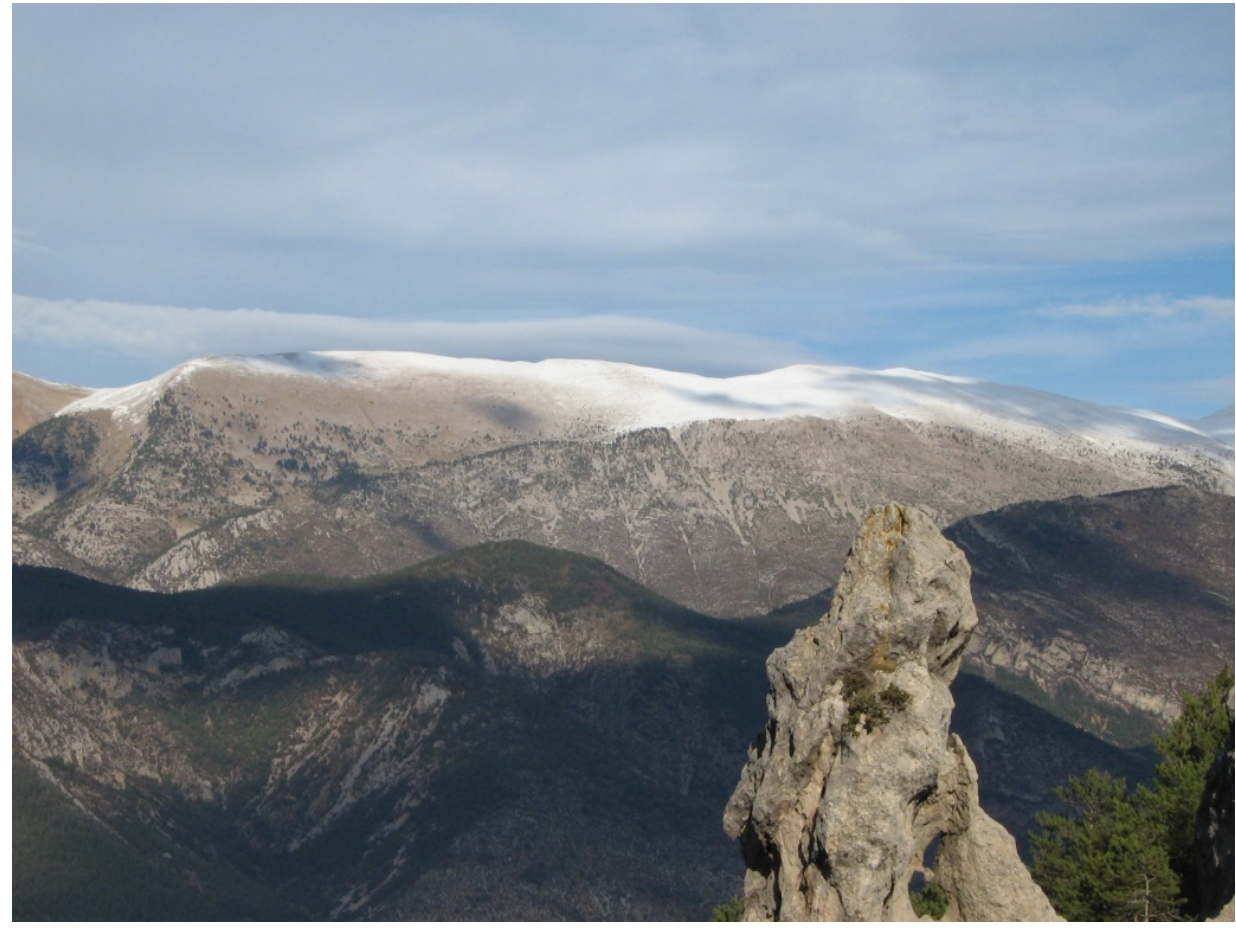

Fotografia 1. En primeríssim terme: les calcàries juràssiques i cretàciques de la Serra del Verd (Mantell del Pedraforca Inferior). En segon i tercer terme: els relleus carbonatats cretàcics dels voltants de Tuixén i el Cadinell (Mantell del Pedraforca Inferior). En darrer terme: les calcàries cenozoiques del la Serra del Cadí (Mantell del Cadí)

Tot això, des del Coll de Port

\subsection{Parada 2. MINA DE BAUXITA DEL COLL DE PORT (termes municipals de Tuixén i de la Coma i la Pedra, comarques de l'Alt Urgell i del Solsonès, respectivament). (Full 254).}

Després de la parada anterior, cal fer un brevíssim recorregut a peu. Així cal agafar un caminat que surt del Port cap al Sud. Aquest camí (situat a l'esquerra de la carretera) és ascendent. En arribar al pla, cal agafar un corriolet que va cap a la carena. Al costat del caminet es troba una antiga explotació, on farem aquesta darrera aturada. Així, haurem recorregut uns $100 \mathrm{~m}$ des del coll.

En aquest breu recorregut, hem anat trobant en tot moment uns afloraments de calcaries mesozoiques del Juràssic. Aquestes calcàries pertanyen al Mantell Inferior del Pedraforca, on estem situats.

Dintre d'elles hi ha mineralitzacions de rebliment de cavitats d'origen kàrstic. Es tracta d'una mineralització d’ $\mathrm{Al}-\mathrm{Fe}$, des del punt de mira del seu quimisme.

Entre els minerals d'alumini presents, cal fer esment dels següents: BOEHMITA (com a bauxita), DIASPOR (bauxita), HIDRARGIRITA (bauxita) i CAOLINITA. També hi ha presència d'ALOMOGEL.

I entre els minerals de ferro, cal esmentar la presència de GOETHITA (en forma de limonita) $i$ HEMATITES (molt abundant, és el mineral que comunica el seu color roig a la bauxita, i a tot el 
conjunt). Finalment, cal dir que en aquest indret es va realitzar una cata de reconeixement, però els resultats no van ésser gaire positius.

Sobre aquestes mineralitzacions es va realitza una cata de reconeixement.. Els resultats no van ésser gens positius. (fotografia 2).

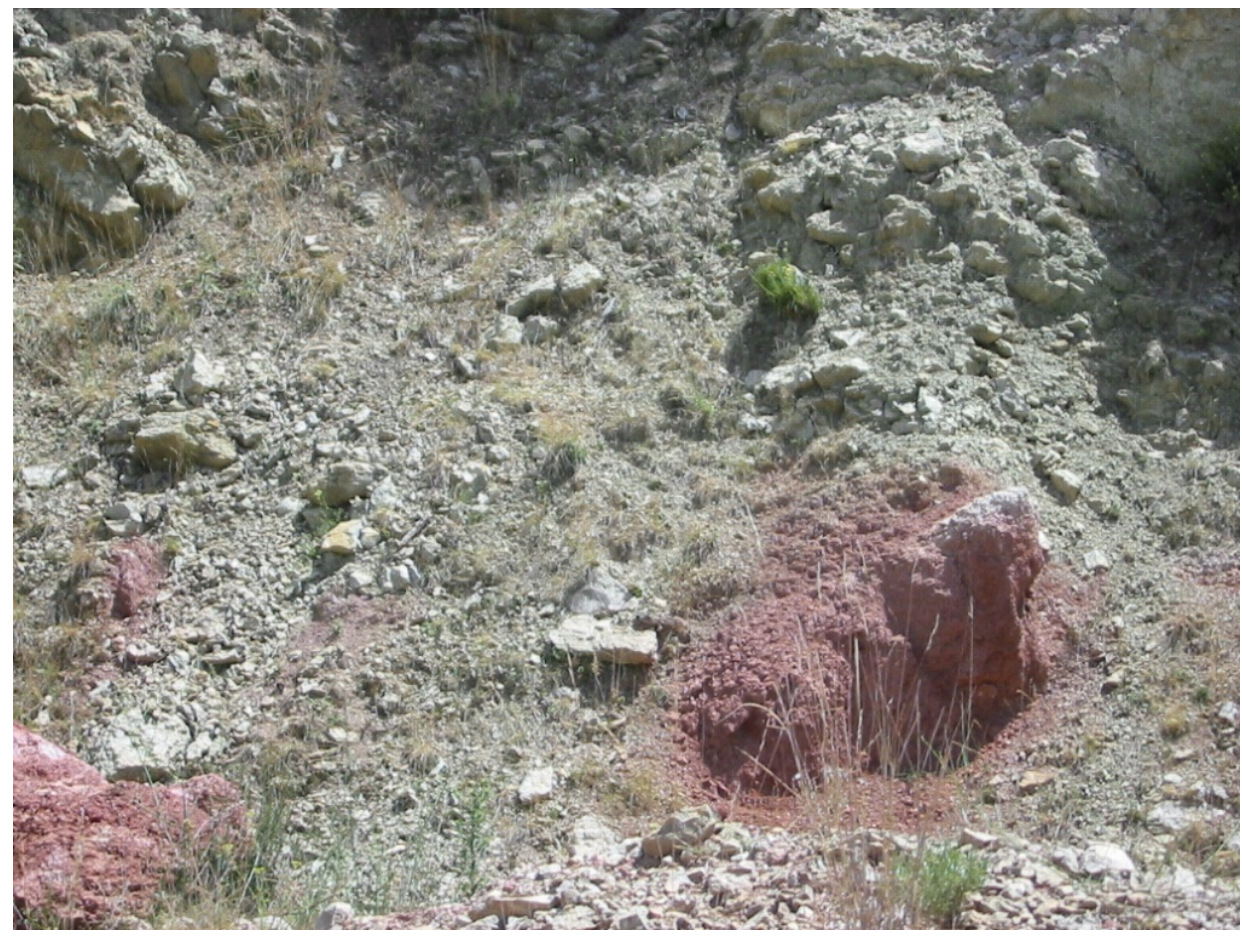

Fotografia 2. Aspecte d'una de les bossades de bauxita

\subsection{Parada 3. MIRADOR DEL PORT DE COMPTE, (terme municipal de la Coma, comarca del Solsonès). (Full 254).}

Després de realitzar l'aturada anterior, cal continuar per la carretera local LV - 4012, baixant cap a la Coma. Tot i així, en trobar la carretera que es dirigeix cap a les instal-lacions de Port del Compte, ens caldrà agafar-la. Així arribarem a l'estació hivernal. Després, ens caldrà continuar per la carretera, per tal d'arribar a l'indret on hi ha les antenes de televisió (a poc més de $1^{\prime} 5 \mathrm{Km}$ del Port de Compte). En aquest indret farem una nova aturada, la darrera del recorregut d'aquest itinerari, a poc més de $10^{\prime} 5 \mathrm{Km}$ de l'anterior.

En aquest recorregut haurem estat circulant en tot moment, entre els materials cenozoics del Mantell del Cadí, que hem trobar al Coll de Port, a la darrera aturada. Així, ara, en aquest indret es poden veure fàcilment les calcàries amb alveolines, al costat de la carretera, on ens trobem ara situats.

Des d'aquest indret, mirant cap a llevant, es pot veure l'explotació de guixos de Guixers, situada entre afloraments dels guixos eocènics, dintre del Mantell del Cadí. Es tracta d'una interesant explotació de guixos, molt ben portada, amb un limitat impacte ambiental. (fotografia 3). 


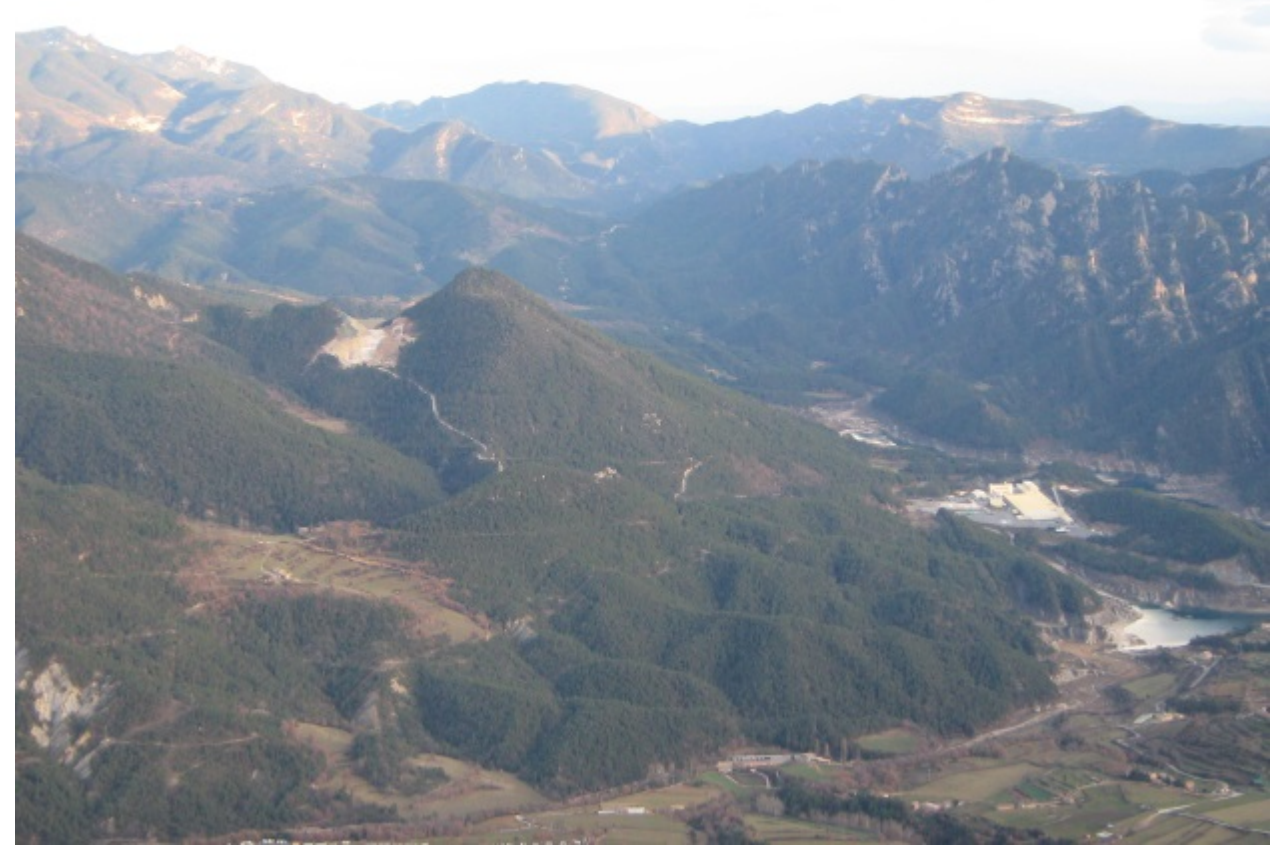

Fotografia 3. L’explotació de guixos eocènics i la Serra de Bastets (amb conglomerats pretectònics

Per altra banda, mirant cap al Sud d'on ara som, es pot veure (en primer terme) la Depressió de Sant Llorenç de Morunys, de caràcter erosiu, ja que es troba sobre uns afloraments de les calcolutites gris - blavoses. Més cap el Sud, es poden veure els relleus de la Serra de Bastets, en franca discordança progressiva amb els materials de la Serra de Busa.

En ambdós indrets, hi afloren els nivells detrítics del conglomerats oligocènics. Aquests materials, a la Serra de Bastets, són clarament pretectònics; mentre que a la Serra de Busa, són en bona part posttectònics. I alhora es pot veure com a la darrera serra, dibuixen un sinclinal: I'anomenat Sinclinal de Busa. (fotografia 4). 


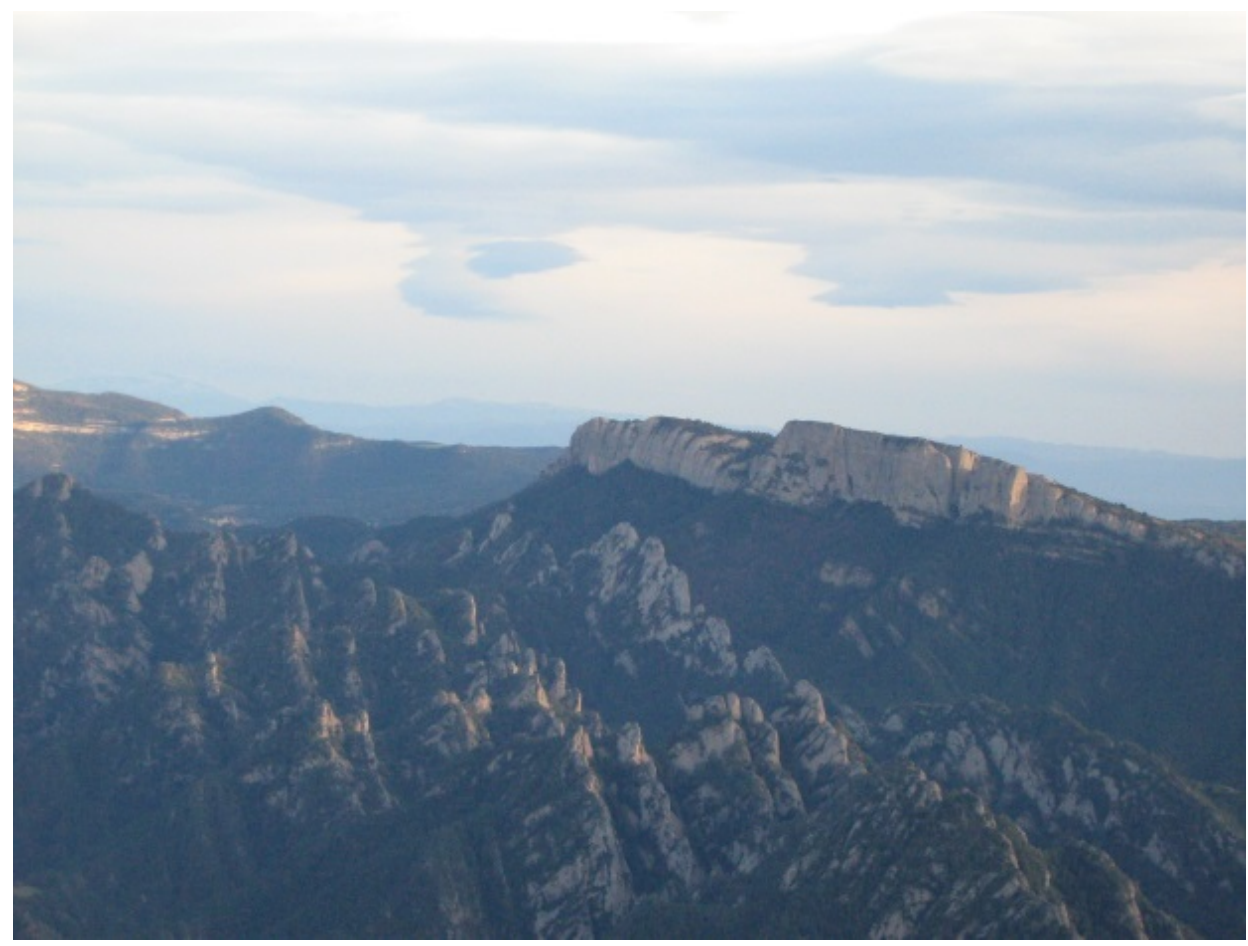

Fotografia 4. La Serra de Bastets (amb conglomerats pretectònics) i la Serra de Busa (amb conglomerats posttectònics)

\subsection{Parada 4. EXPLOTACIÓ D'ARIDS DE LA CARRETERA DEL PORT DE COMPTE, (terme municipal de la Coma, comarca del Solsonès). (Full 254).}

Després de realitzar l'aturada anterior, cal continuar per la carretera local que va des de les pistes d'esquí cap a Coll de Jou. A uns $0^{\prime} 2 \mathrm{Km}$ podem fer una nova aturada a la bora de la carretera.

En aquest curt recorregut, no hem deixat el Mantell del Cadí, i a la bora de la carretera, hem anat trobant afloraments dels materials cenozoics de l'Eocè. Així, es fan ben paleses unes calcàries amb alveolines, per tot arreu.

En aquest indret, hi havia una antiga explotació d’àrids per a la construcció. El que explotaven eren els materials de col-luvials de pedemonte, els derrubis de pendent. Evidentment, eren de caràcter carbonatat, bons com a àrids, però l’explotació suposava un greu risc d'esllavissada. 


\subsection{Parada 5. CRUIILLA DE COLLDEJOU, DE LES CARRETERES CAP A SANT LLORENÇ DE MORUNYS (L - 401) I CAP A SOLSONA (L - 4218B), (terme municipal de Guixers, comarca del Solsonès). (Full 292).}

Després de realitzar l'aturada anterior, cal fer un breu recorregut per la carretera procedent de les pistes d'esquí. Per aquesta carretera, en menys de $1 \mathrm{Km}$, arribarem a l'indret on hi ha el Coll de Jou, i on hi ha una important cruilla de carreteres.

En part d'aquest recorregut, hem circulat al peu de la Serra de Querol, la qual forma part dels sectors meridionals del Mantell del Cadí (situat dintre del denominat Pirineu Meridional, abans conegut com a Prepirineu) concretament de la Serra del Port del Compte, que ens queda a l'esquena del recorregut, al nord del nostre recorregut.

Per altra banda, en aquest trajecte, ara hem començat a trobar afloraments dels materials detrítics de I'Oligocè. Aquests materials formen part de la Depressió Geològica de l'Ebre (constituint en part els relleus de l'Avant País Plegat). Per d'altra banda, aquests materials constitueixen els relleus morfològics, no pas estructurals, de la denominada Serra de Canalda, que es situa al Sud del nostre recorregut.

En aquest indret es troba el contacte entre les dues unitats geològiques abans esmentades. Aquest contacte es produeix per un encavalcament de la Serra de Querol sobre la Serra de Canalda: es a dir: del Pirineu Meridional sobre la Depressió Geològica de I'Ebre. Tot i així, no es prou visible aquest contacte, ja que la discordança progressiva dels materials cenozoics de I'Oligocè, fa que els nivells més recents, de caràcter postorogènics cobreixen el contacte. (fotografia 5).

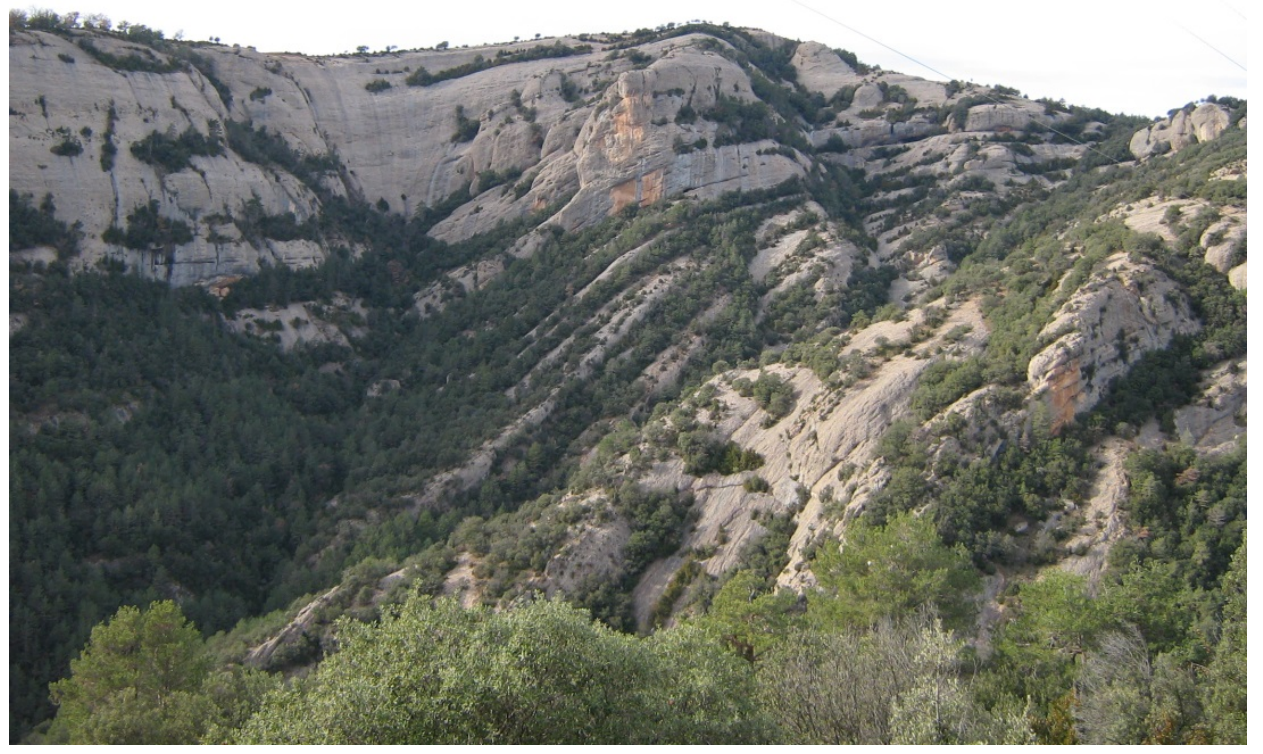

Fotografia 5. Un aspecte de la discordança progressiva de la Creu de Codó prop de Coll de Jou. Aflorament conglomerats oligocènics posttectònics 
Per altra banda, cal dir que aquest contacte es realitza a través d'una làmina dels materials del Keuper (del Triàsic Superior) sobre la qual rellisquen els materials eocènics de la Serra de Querol. Aquests materials del Keuper no arriben a aflorar a l'indret de l'aturada, tot i així, en el barranc que baixa cap a Sant Llorenç de Morunys, hi ha diverses fonts d'aigua salada, procedents de la lixiviació dels materials del Keuper per les aigües superficials.

\subsection{Parada 6. CORVA DEL CLOT DE VILAMALLA, CARRETERA A SOLSONA, L - 4218B, Km 22, (terme municipal de Guixers, comarca del Solsonès). (Full 292).}

Després de realitzar I'aturada anterior, cal fer un breu recorregut per la carretera local L 4218B, fins arribar a les immediacions de l'antic $\mathrm{Km} \mathrm{22}$, per on farem una nova aturada, a uns $2 \mathrm{Km}$ de la parada anterior, per sota de Creu de Codó. I a la mateixa distancia de la parada realitzada anteriorment.

En aquest recorregut, hem trobat afloraments dels nivells superiors dels conglomerats oligocènics, els quals reblen la Depressió Geològica de l'Ebre, on ara som. Aquí, aquests relleus donen lloc a la Serra de Canalda, situada a ponent d'on som. Aquests materials es situen, en part, dintre de l'anomenat Avant País Plegat, que jas hem esmentat anteriorment.

Des d'aquest indret, es pot gaudir d'una bona observació dels materials oligocènics situats a llevant. Aquests materials formen part de la Serra de Bastets (al Nord) i de la Serra de Busa (al Sud). Així es pot veure la discordança progressiva, que hi ha entre ambdues serres. També, des d'aquest privilegiat indret es pot veure el Sinclinal de Busa, que a l'altra banda del riu es veu continuat pel Sinclinal del lord, de dimensions molt més reduïdes (fotografia 6).

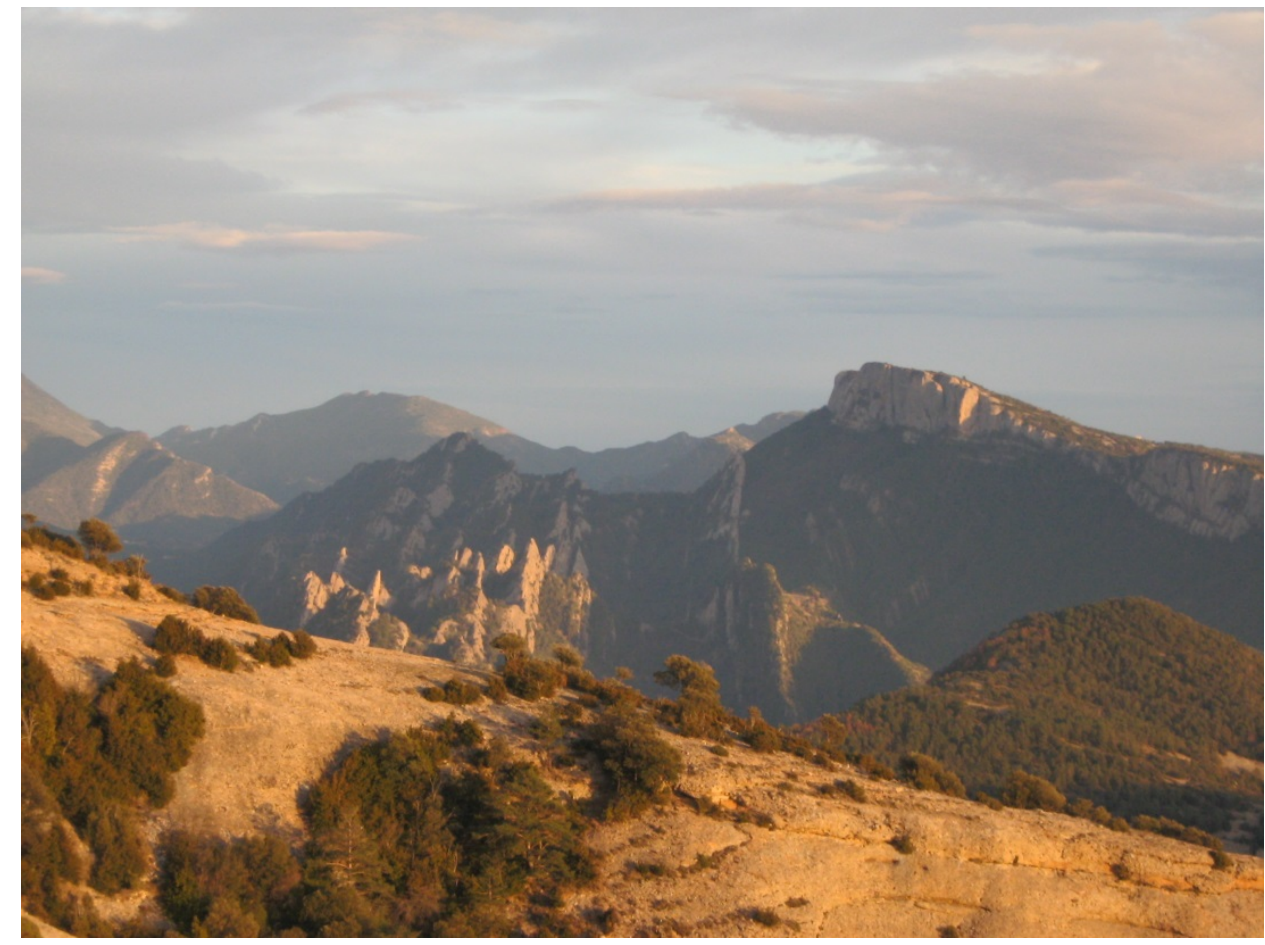

Fotografia 6.

Contacte entre la Serra de Bastets (al nord), amb la Serra de Busa (al Sud, a la dreta) Es veu com la Serra de Busa te una lleugera inflexió, que correspon al seu sinclinal.. Aquest contacte es realitza mitjançant una discordança progressiva. 
En aquest indret finalitza el recorregut de l'itinerari

\section{Bibliografia}

BERASTEGUI, X. et altri ( 1993).- Tall geològic del Pirineu central. Servei Geològic de Catalunya, Institut Cartogràfic de Catalunya. Col/lecció 1:200.000. Barcelona.

GUIMERÀ, J. et altri (1992).- Geologia (II), Història Natural dels Països Catalans, Vol. 2, 547 pag. Enciclopèdia Catalana, S.A. Barcelona.

MATA-PERELLÓ, J.M. (1991).- Els Minerals de Catalunya. Arxius de la Secció de Ciències, t. XCIII, 442 pag. Institut d’Estudis Catalans. Barcelona.

MATA-PERELLÓ,J.M. (1997a).- Itinerari geològico - mineralògic per I'Alt Urgell: de Tuixén a Tres Ponts. Inèdit, 8 pag. Manresa.

MATA-PERELLÓ,J.M. (1997b).- Recerca geològica i mineralògica per les comarques del Solsonès i de l'Alt Urgell: des de Sant Llorenç de Morunys al Coll del Port i a Tuixén. Inèdit, 11 pag. Manresa.

MATA-PERELLÓ,J.M. (2005).- Recorregut de recerca geològica i mineralògica per les comarques del Solsonès i de I'Alt Urgell: des de Solsona a Alinyà i a la Vansa. Inèdit, 10 pag. Manresa.

MATA-PERELLÓ,J.M. (2007).- Recorregut de recerca geològica i mineralògica per les comarques de la Cerdanya, Alt Urgell i Solsonès: des de Martinet i Arenys de Bar a Toloriu, Tuixén i al Coll de Port. Inèdit, 10 pag. Manresa.

MATA-PERELLÓ,J.M. (2012).- Recorregut de recerca geològica, mineralògica i minera per les comarques del Berguedà, Alt Urgell i Solsonès: des de Vallcebre a Gósol, Josa del Cadí, Tuixén i al Port de Compte. Inèdit, 8 pag. Manresa.

MATA-PERELLÓ,J.M. (2013a).- Recorregut de recerca geològica i geoambiental per la comarca del Solsonès: des de Solsona a la Llosa del Cavall, a Sant Llorenç de Morunys i al Port del Compte. Inèdit, 14 pag. Manresa.

MATA-PERELLÓ,J.M. (2013b).- Recorregut de recerca geològica i mineralògica per la comarca del Solsonès: des de Cambrils a Odèn i al Colldejou. Inèdit. 14 pàgines. Manresa.

MATA-PERELLÓ, J.M. i SANZ BALAGUÉ, J. (1993).- Guia de Identificación de Minerales, adaptada fundamentalmente a la Península Ibérica. Parcir, Edicions Selectes. 205 pàgines. Manresa.

MATA-PERELLÓ, J.M. i SANZ BALAGUÉ, J. (2014).- Recorregut de recerca geològica i mineralògica per la comarca de I'Alt Urgell (amb una petita fillola per la comarca del Solsonès): des de la Vansa a Fórnols de Cadí, Cornellana, Tuixén i al Coll del Port. Inèdit. 12 pàgines. Manresa.

RIBA ARDERIU, O. Et altri. (1976).- Geografia Física dels Països Catalans. Edit Ketres, 254 pàgines. Barcelona.

SGC (1990).- Mapa Geològic de Catalunya a escala 1:250.000, Servei Geològic de Catalunya (Inst. Cartograf. de Catalunya). Barcelona. 